\title{
Interactive Training and Education Improves Basic Hypertension Knowledge of Woman Cadres in Surabaya
}

\author{
Andrianto Andrianto*, Meity Ardiana, Muhammad Aditya, Sondang Jasmine Sitorus, Dita Aulia Rachmi, Imanita Septianda, \\ Makhyan Jibril Al-Farabi \\ Department of Cardiology and Vascular Medicine, Faculty of Medicine, University of Airlangga, Surabaya, Indonesia
}

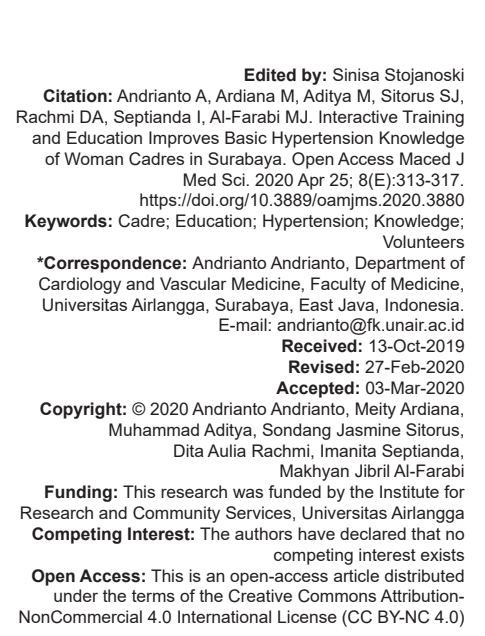

\section{Abstract}

BACKGROUND: Hypertension is the major risk factor for cardiovascular disease, a leading cause of premature death and disability. Interactive education and training are potentially used to improve hypertension knowledge.

AIM: This study aimed to identify the impact of training and education programs toward knowledge in hypertension for women cadres.

METHODS: This quasi-experimental study was conducted in Surabaya, Indonesia, involving 100 women cadre. The data were collected through interviews, pre- and post-training using a validated researcher-made questionnaire of demographic characteristics, and knowledge tests of hypertension. Data were analyzed using SPSS 21.

RESULTS: Knowledge of cadre was significantly increased by $50 \%$ after the training and education program $(p<0.001)$. The median score of the pre-test and post-test was $40.00(30.00-50.00)$ and $60.00(50.00-70.00)$ respectively. The level of education found to have a negative correlation with the post-test score $(p=0.008)$. There was no difference in knowledge increment after training among age groups $(p=0.261)$, marital status $(p=0.849)$ or occupations type $(p=0.827)$

CONCLUSION: Training and education programs significantly improve the hypertension knowledge of woman cadre. This method can be a preferable early public health intervention to tackle hypertension.

\section{Introduction}

Hypertension is one of the most common worldwide diseases affecting humans which act as a major risk factor for myocardial infarction, stroke, vascular disease, and chronic kidney disease [1]. Hypertension has become a global burden for its associated morbidity, mortality, and cost to society. Thus, prevention and management of hypertension are major public health challenges [2], [3], [4]. The global burden of hypertension is estimated to rise from 0.9 billion in 2000 to 1.6 billion in 2025 [5]. In 2016, 17.9 million deaths globally are due to cardiovascular disease with hypertension as the leading risk factor [6]. In Indonesia, ischemic heart disease and cerebrovascular disease are the leading causes of disability-adjusted life years lost in 2016 [7].

The survey from the Indonesian Health Ministry in 2018 of non-communicable disease revealed that $8.8 \%$ of an adult age 18 years old and above had hypertension. About $32.3 \%$ of the population were not taking medicine routinely and $13.3 \%$ not taking any medicine at all. The two most common reasons for this improper behavior are asymptomatic patient with hypertension usually perceive themselves as healthy and not routinely going to health-care facilities [8]. These facts showed that sufficient hypertension education is important to ensure optimum hypertension control in society. This strategy is consistent with the government policy which prioritizes health promotion and community development a strategic plan of the Indonesian Health Ministry [9].

Interactive education and workshops are considered as one of the most effective strategies in community-based health education programs in improving knowledge [10]. However, to achieve behavioral change, this approach should be delivered specifically to the correct segment. Conventionally, women as a mother and wife spending most of their time at home to fulfill the needs of their family [11]. In Indonesian culture, women have a central role in the family. They take responsibility for arranging the daily menu, cooking for the family, having an awareness of sick family members, and even being as decisionmaker whether it needs to seek medical help [12]. Through their influence, women will be able to influence the family diet and behavior. In addition, women cadre 
is socially connected with various community groups, including the elderly and their neighborhoods who are susceptible to and suffer from hypertension [12]. Women will able to recognize those who need more attention and can act accordingly [12]. Hence, women cadre can be a great candidate to become the frontline health agent to the community and receive proper education about hypertension.

Data form the Health Office of Surabaya Government stated that Mojo district had the third-highest prevalence of hypertension among 68 other districts in Surabaya in 2018. Unfortunately, only $6.43 \%$ of the Mojo population has proper hypertension treatment [13]. Based on this finding, we aim to increase community awareness of hypertension, especially in Mojo district, Surabaya, through training and education in women cadre. In this research, we evaluate the impact of interactive education and workshops on the hypertension knowledge of women cadre.

\section{Materials and Methods}

\section{Design}

This one-group pretest-posttest quasiexperimental was conducted in the Mojo district, Surabaya, Indonesia. One hundred women cadres (a neighborhood-based non-physician community health care worker) were invited using quota sampling from 13 neighborhood in the Mojo district. The inclusion criteria were female which has been worked as healthcare cadre in the Mojo region. Exclusion criteria were cadres who were not willing to participate in the study and cadres who did not attend the whole program.

The data were collected using a validated researcher-made questionnaire of demographic characteristics and knowledge tests of hypertension, through interviews pre- and post-training and education programs. Data collection included demographic characteristics. Age was categorized into three groups (29-45 years old; 46-59 years old; and >60 years old). Marital status was categorized into three groups (unmarried; married; and widow). For education level, junior high school or less was labeled as primary education level, while senior high school or higher was labeled as secondary education level. For occupation, the cadre who did not work and only took care of the house was labeled as a housewife, while occupation other than housewife was labeled as non-housewife.

The hypertension knowledge test consisted of 20 questions including definition, etiology, classification, symptoms, risk factors, complications, prevention, treatment, and diet in hypertension. The validity of the hypertension knowledge test was analyzed using factor analysis with $\mathrm{KMO}$ and Bartlett's test $(\mathrm{p}=0.003)$, and the reliability was analyzed using Kuder-Richardson Formula 20 (rKR20 = 0.72). The baseline knowledge of hypertension (pre-test) was collected through interviews. The post-test was collected after the third session.

\section{Ethical clearance}

The research was conducted in accordance with the Helsinki Declaration of 1975 as revised in 2000. All participating patients have signed written informed consent. The study protocol has been approved by the local ethics committee. Data that show patient personal information were omitted.

\section{The educational and training program}

Women cadre was taught and trained by qualified cardiology residents. Cadres took educational and training programs for $3 \mathrm{~h}$ session once a month, for 3 months. The first session was about the basic knowledge of hypertension including definition (according to JNC 8), signs and symptoms, risk factors, complications, management, prevention, and follow-up intervals. The second session focused more on the implementation of the DASH diet. The DASH diet educational material in this program focused on the application of daily salt restrictions using a $5 \mathrm{~g}$ measuring spoon and the food ingredients selection for daily cooking for hypertension. At the end of the session, a cooking demonstration of two types of food was carried out using predominantly vegetable and egg ingredients and salt of fewer than $5 \mathrm{~g} \mathrm{a}$ day. The third session highlighted the exercises for hypertension. The exercise education material in this program focused on the type of exercise, duration, and frequency of exercise for hypertension. A healthy heart exercise demonstration consisted of a warm-up, core, and cooling movements. We choose those topics based on the latest recommendation from Centers for Disease Control and Prevention [14].

In each session, cadres were asked to review the previous materials and trained on how to measure blood pressure using a sphygmomanometer. Blood pressure measurement training was done in groups. Cadres were divided into 10 groups; each group was accompanied by three trainers. Blood pressure was measured using a sphygmomanometer and a stethoscope. The procedure for measuring blood pressure was as follows: Subject in a sitting position, arm at heart level, and set the cuff on the upper arm with lower edge cuff at 1 inch above the antecubital fossa. Place the diaphragm stethoscope just below the lower edge of the cuff. Check the radial pulse, expand the cuff until the radial pulse is not palpable, look at the pressure on the sphygmomanometer then add $30 \mathrm{mmHg}$, listen using the stethoscope while gently releasing air from the cuff. The first knock sound (Korotkoff) is the subject's 
systolic pressure. When the knocking sound ends, that is the subject's diastolic pressure.

\section{Statistical analysis}

Data were analyzed using SPSS statistical software for Windows, version 21. Data analysis was performed by comparing the pre-test and post-test knowledge score, and their relationship with sociodemographic characteristics. A paired t-test was used to analyze the mean difference between pre- and post-test knowledge scores, while the Wilcoxon test was used as alternatives. The analysis of mean differences between sociodemographic groups used independent t-test, while the Mann-Whitney U-test or Kruskal-Wallis test was used as an alternative if the data were not normally distributed. Continuous data were presented as mean and standard deviation, or median and interquartile range (IQR) if the data were not normally distributed. Categorical data were presented as proportion. The significance level used was 0.05 and a confidence interval $95 \%$.

\section{Results}

A total of 97 women cadre, of the Mojo district, Surabaya, attended the hypertension interactive education and training, three cadres refused to participate. Their mean age was 49.09 \pm 8.48 years. Most of them are married (81 of 94 , $86.17 \%$ ); finished senior high school education (62 of $94,65.96 \%$ ); and as a housewife (80 of $94,85.11 \%$ ). The demographic characteristic of the women cadre is shown in Table 1.

Table 1: Demographic characteristics of the women cadre $(n=94)$

\begin{tabular}{ll}
\hline Variable & $\mathrm{n}$ \\
\hline Age, mean \pm SD & $49.09 \pm 8.48$ \\
Marital status, $\mathrm{n}(\%)$ & \\
$\quad$ Unmarried & $2(2.13)$ \\
Married & $81(86.17)$ \\
Widow & $11(11.70)$ \\
Education level, $\mathrm{n}(\%)$ & \\
$\quad$ Not completed primary school & $1(1.06)$ \\
Primary school & $1(1.06)$ \\
Junior high school & $21(22.34)$ \\
Senior high school & $62(65.96)$ \\
Associate degree (D3) & $3(3.19)$ \\
Undergraduate & $6(6.38)$ \\
Occupation, $\mathrm{n}(\%)$ & $1(1.06)$ \\
Civil servants & $1(1.06)$ \\
Employee of private sector & $5(5.32)$ \\
Entrepreneur & $3(3.19)$ \\
Retired & $80(85.11)$ \\
Housewife & $4(4.26)$ \\
Other & \\
\hline
\end{tabular}

Post-test scores (median 60.00; IQR 50.00-70.00) knowledge of hypertension in the cadres increased significantly compared to pre-test scores (median 40.00; IQR 30.00-50.00), as shown in Table 2. Post-test results are still not optimal on several questions, as shown in Table 3. The suboptimal understanding of hypertension included asymptomatic hypertension, unmodifiable risk factors of hypertension, untrue statements about the risk factors of hypertension, iatrogenic causes of hypertension, hypertension therapy, and what should be done if one suffers from hypertension.

Table 2: Pre- and post-test scores of hypertension knowledge of women cadre $(n=94)$

\begin{tabular}{lllll}
\hline $\begin{array}{l}\text { Hypertension } \\
\text { knowledge score }\end{array}$ & Mean \pm SD & Median (IQR) & $\begin{array}{l}\text { Mean } \\
\text { difference }\end{array}$ & $\mathrm{p}^{*}$ \\
\hline $\begin{array}{l}\text { Pre-test score } \\
\text { Post-test score }\end{array}$ & $42.82 \pm 15.25$ & $40.00(30.00-50.00)$ & $17.55 \pm 14.00$ & $<0.001$ \\
\hline${ }^{*}$ Wilcoxon signed-rank test. & & & & \\
\hline
\end{tabular}

Table 4 shows the association between sociodemographic factors in women cadre and the score of hypertension knowledge post-interactive education and training program (post-test score). There was a significant difference in the post-test scores between the primary education level and secondary education level.

\section{Discussion}

From this study, training and education programs were shown to significantly increase the cadre's knowledge. The data showed that the pre-test median score was 40.00 , while the post-test was 60.00 . Statistical analysis showed significant increase in the level of knowledge by $50 \%$. This median post-test score of basic hypertension knowledge was 60.00 which can be categorized as a moderate level of knowledge [15]. This result was consistent with the previous study that evaluates the effect of interactive education and workshop improved the post-test score between 3\% and $40 \%$ [16], [17], [18], [19], [20]. Interestingly, this study showed higher post-intervention knowledge score than other previous studies.

In the post-test score evaluation, the question about asymptomatic hypertension had the fewest number of participants with the right answer (9.57\%). Interestingly, most of the women cadre could identify symptoms which are not related to hypertension $(95.88 \%)$. This contradictive finding suggests an uncomprehensive understanding of the signs and symptoms of hypertension among women cadres. In addition, the influence of hypertension myths could further distort their understanding. One of the popular myth said that renal disease can be occurred due to prolonged use of the hypertensive drug. Before training, $74.47 \%$ of participants believed that longterm consumption of antihypertensive agent can cause kidney disease. After the training, the percentage was greatly reduced to $27.66 \%$ (Table 3 , item number 19 ).

Fifteen out of 20 questions were answered incorrectly by more than $50 \%$ of participants before training. However, after training, it remained only seven 
Table 3: Pre- and post-test correct response comparison of hypertension knowledge

\begin{tabular}{|c|c|c|c|c|}
\hline \multirow[t]{2}{*}{ Item number } & \multirow[t]{2}{*}{ Question } & \multicolumn{2}{|c|}{ Number of respondents with the correct answer (\%) } & \multirow[t]{2}{*}{$\mathrm{p}^{*}$} \\
\hline & & Pre-test $(n=94)$ & Post-test $(n=94)$ & \\
\hline 1 & Definition of hypertension according to the latest guideline & $34(36.17)$ & $81(86.17)$ & $<0.001$ \\
\hline 2 & Asymptomatic hypertension & $9(9.57)$ & $22(23.40)$ & 0.005 \\
\hline 3 & Etiology of primer hypertension & $49(52.13)$ & $71(75.53)$ & 0.001 \\
\hline 4 & Hypertension classification & $59(62.77)$ & $74(78.72)$ & 0.007 \\
\hline 5 & Definition of secondary hypertension & $59(62.77)$ & $76(80.85)$ & 0.002 \\
\hline 6 & Unmodifiable risk factor of hypertension & $21(22.34)$ & $38(40.43)$ & 0.002 \\
\hline 7 & Modifiable risk factor of hypertension & $28(29.79)$ & $54(57.45)$ & $<0.001$ \\
\hline 8 & Etiology of hypertension & $24(25.53)$ & $42(44.68)$ & 0.005 \\
\hline 9 & Unrelated symptoms of hypertension & $90(95.74)$ & $92(97.87)$ & 0.157 \\
\hline 10 & latrogenic cause of hypertension & $27(28.72)$ & $33(35.11)$ & 0.273 \\
\hline 11 & Hypertension complication & $72(76.60)$ & $92(97.87)$ & $<0.001$ \\
\hline 12 & Primary prevention of hypertension & $31(32.98)$ & $52(55.32)$ & 0.001 \\
\hline 13 & Secondary prevention of hypertension & $27(28.72)$ & $21(22.34)$ & 0.289 \\
\hline 14 & Frequency of visiting medical health care for routine follow-up for people who suffer from hypertension & $30(31.91)$ & $52(55.32)$ & $<0.001$ \\
\hline 15 & Hypertension therapy & $13(13.83)$ & $34(36.17)$ & $<0.001$ \\
\hline 16 & Non-pharmacology therapy of hypertension & $40(42.55)$ & $54(57.45)$ & 0.023 \\
\hline 17 & Diet plan recommendation for hypertension & $84(89.36)$ & $71(75.53)$ & $<0.001$ \\
\hline 18 & Management of hypertension & $39(41.49)$ & $49(52.13)$ & 0.096 \\
\hline 19 & Myth about hypertension & $24(25.53)$ & $68(72.34)$ & $<0.001$ \\
\hline 20 & The right way to measure blood pressure & $45(47.87)$ & $59(62.77)$ & 0.011 \\
\hline
\end{tabular}

questions that incorrectly answered. Topics that remain poorly understood were asymptomatic hypertension, the unmodifiable risk factor of hypertension, etiology of hypertension, iatrogenic cause of hypertension, secondary prevention of hypertension, hypertension therapy, and management of hypertension. Thus, we need to try different types of approaches and a more intense learning method to improve their understanding of these particular topics.

Table 4: Post-test score difference based on sociodemographic characteristics

\begin{tabular}{|c|c|c|c|c|}
\hline Variable & Frequency & Mean \pm SD & Median (IQR) & $p$ \\
\hline \multicolumn{5}{|l|}{ Age } \\
\hline 29-45 years old & 29 & $57.59 \pm 13.27$ & $55.00(50.00-67.50)$ & \multirow[t]{3}{*}{$0.261^{*}$} \\
\hline $46-59$ years old & 54 & $60.93 \pm 16.54$ & $60.00(55.00-71.25)$ & \\
\hline$>60$ years old & 11 & $65.00 \pm 11.83$ & $65.00(55.00-75.00)$ & \\
\hline \multicolumn{5}{|l|}{ Marital status } \\
\hline Unmarried & 2 & $57.70 \pm 3.54$ & $57.50(55.00-60.00)$ & \multirow[t]{3}{*}{$0.849^{*}$} \\
\hline Married & 81 & $60.68 \pm 15.14$ & $60.00(55.00-70.00)$ & \\
\hline Widow & 11 & $58.64 \pm 17.04$ & $65.00(45.00-72.50)$ & \\
\hline \multicolumn{5}{|l|}{ Level of education a } \\
\hline Primary education level & 23 & $67.61 \pm 12.96$ & $70.00(60.00-75.00)$ & \multirow[t]{2}{*}{$0.008^{*}$} \\
\hline Secondary education level & 71 & $58.03 \pm 15.13$ & $60.00(50.00-70.00)$ & \\
\hline \multicolumn{5}{|l|}{ Occupation } \\
\hline Housewife & 80 & $60.06 \pm 15.74$ & $60.00(50.00-70.00)$ & \multirow[t]{2}{*}{$0.827^{*}$} \\
\hline Non-housewife & 14 & $62.14 \pm 11.39$ & $60.00(55.00-71.25)$ & \\
\hline
\end{tabular}

From sociodemographic data, we found that there was no difference in knowledge score after training between age groups ( $p=0.261)$. The post-test median scores of cadre age 29-45 years old, 46-59 years old, and $>60$ years old were 55.00 (50.00-67.50), 60.00 (55.00-71.25), and 65.00 (55.00-75.00), respectively. However, in this study, the level of education correlated with the post-test score paradoxically $(p=0.008)$. Cadres with primary education level had a mean score of 67.61 \pm 12.96 , while secondary education level was $58.03 \pm$ 15.13. This finding might be due to the willingness to learn as an individual was more related to motivation than age or level of education factors [21], [22].

The demographic association with the knowledge level of hypertension in this study was similar to the previous study in Jakarta. A study by Fatmah showed no association in knowledge after training in different age groups. However, there was a higher increment of a score in primary than in secondary education level [19]. In contrary, these findings were different in a study by Pantip. This study found that the level of education has a positive correlation with the increment of knowledge after training, while age was negatively correlated [18]. Furthermore, in this study, we found that occupational status did not correlate with knowledge improvement (Table 4).

There were some limitations in our study which should be taken into account in the interpretation. The limited sample size might affect the lack of significance in the correlation between demographic factors and knowledge level. Since the data were collected from a single location, the result may not be able to be generalized to other populations. This study also only evaluates the effect of training and education on the knowledge after interactive education and training, rather than its real impact on hypertension in the community. Therefore, future studies should be done using more samples from various locations to evaluate the benefit of hypertension knowledge improvement in the women cadre toward public awareness of hypertension and willingness to control their lifestyle and compliance with hypertension treatment [23].

\section{Conclusion}

Interactive education and training can significantly improve the basic knowledge of hypertension for women cadre.

\section{References}

1. World Health Organization. A Global Brief on Hypertension: Silent Killer, Global Public Health Crisis. Geneva: World Health Organization; 2013. 
2. National Institue of Health, National Heart Lung and Blood Institute, and National High Blood Pressure Education Program. The Seventh Report of the Joint National Commitee on Prevention, Detection, Evaluation, and Treatment of High Blood Pressure. Bethesda: National Institue of Health; 2004. https:// doi.org/10.1037/e442802008-001

3. Roth GA, Johnson C, Abajobir A, Abd-Allah F, Abera SF, Abyu G, et al. Global, regional, and national burden of cardiovascular diseases for 10 causes, 1990 to 2015. J Am Coll Cardiol. 2017;70(1):1-25.

PMid:28527533

4. Benjamin EJ, Blaha MJ, Chiuve SE, Crushman M, Das SR, Deo R, et al. Heart disease and stroke statistics 2017 update:Areportfrom the american heart association. Circulation. 2017;135(10):146$603 . \quad$ https://doi.org/10.1161/cir.0000000000000491 PMid:28122885

5. Kearney PM, Whelton M, Reynolds K, Muntner P, Whelton PK, He J. Global burden of hypertension: Analysis of worldwide data. Lancet. 2005;365(9455):217. https://doi.org/10.1016/ s0140-6736(05)17741-1

PMid:15652604

6. World Health Organization. Global Health Observatory: Mortality and Morbidity. Geneva: World Health Organization; 2012.

7. Mboi N, Surbakti IM, Trihandini I, Elyazar I, Smith KH, Ali PB, et al. On the road to universal health care in Indonesia, 19902016: A systematic analysis for the global burden of disease study 2016. Lancet. 2018;392(10147):581-91. https://doi. org/10.1016/s0140-6736(18)30595-6

PMid:29961639

8. Kementerian Kesehatan Republik Indonesia. Hasil Utama Riskesdas 2018. Jakarta: Kementerian Kesehatan Republik Indonesia; 2018.

9. Kementerian Kesehatan Republik Indonesia. Rencana Strategis Kementerian Kesehatan Tahun 2015-2019; 2019. Available from: http://www.depkes.go.id/resources/download/info-publik/ Renstra-2015.pdf. [Last accessed on 2019 Sep 12].

10. Lu CH, Tang ST, Lei $Y X$, Zhang MQ, Lin WQ, Ding SH, et al. Community-based interventions in hypertensive patients: A comparison of three health education strategies. BMC Public Health. 2015;15:33. https://doi.org/10.1186/s12889-015-1401-6 PMid:25631224

11. Lantara NF. The roles of woman as leader and housewife. J Def Manag.2015;5:125.https://doi.org/10.4172/2167-0374.1000125

12. Kementerian Kesehatan Republik Indonesia. Pedoman Umum Pengelolaan Posyandu. Jakarta: Kementerian Kesehatan Republik Indonesia; 2011.

13. Dinas Kesehatan Kota Surabaya. Standar Pelayanan Medis Pelayanan Penderita Hipertensi Kota Surabaya Tahun 2018. Surabaya: Dinkes Kesehatan Kota Surabaya; 2018. https://doi. org/10.24198/jmpp.v1i2.19895
14. Centers for Disease Control and Prevention. Preventing High Blood Pressure: Healthy Living Habits; 2014. Available from: https://www.cdc.gov/bloodpressure/healthy_living.htm. [Last accessed on 2019 Sep 12].

15. Nur AM, Azfar M, Omarulharis S, Azfar H, Maryam A, Hafizah S, et al. Knowledge, attitude, and practice of dengue prevention among sub urban community in Sepang, Selangor. Int J Public Heal Clin Sci. 2017;4(2):73-83.

16. Abdel-All M, Thrift AG, Riddell M, Thankappan KR, Mini GK, Chow $\mathrm{CK}$, et al. Evaluation of a training program of hypertension for accredited social health activists (ASHA) in rural India. BMC Health Serv Res. 2018;18(1):1-11. https://doi.org/10.1186/ s12913-018-3140-8 PMid:29720161

17. Abdel-All M, Putica B, Praveen D, Abimbola S, Joshi R. Effectiveness of community health worker training programmes for cardiovascular disease management in lowincome and middle-income countries: A systematic review. BMJ Open. 2017;7(11):e015529. https://doi.org/10.1136/ bmjopen-2016-015529 PMid:29101131

18. Sangprasert $P$. The effects of a training program for the development of hypertension knowledge and basic skills practice (HKBSP) for Thai community healthcare volunteers. Siriraj Med J. 2011;63:163-7.

19. Fatmah F, Nasution $Y$. Peningkatan pengetahuan dan keterampilan kader posbindu dalam pengukuran tinggi badan prediksi lansia, penyuluhan gizi seimbang dan hipertensi studi di kecamatan Grogol, Petamburan, Jakarta Barat. Media Med Indones. 2012;46(1):61-8. https://doi.org/10.37012/jik.v10i1.15

20. Noda A, Obara T, Takada K, Kishikawa Y, Abe S, Yoshimachi S, et al. Changes in community pharmacists' knowledge, attitudes, and practice regarding the management of hypertension before and after educational interventions. Clin Exp Hypertens. 2020;42(4):3227. https://doi.org/10.1080/10641963.2019.1652634

PMid:31423854

21. Remali AM, Ghazali MA, Kamaruddin MK, Kee TY Understanding academic performance based on demographic factors, motivation factors and learning styles. Int J Asian Soc Sci. 2013;3(9):1938-51.

22. Salwa A, Raiz S. Impact of grade sensitivity on learning motivation and academic performance. Int J Educ Pedagog Sci. 2016;10(7):2315-9.

23. Patel A, Praveen D, Maharani A, Oceandy D, Pilard Q, Kohli MP, et al. Association of multifaceted mobile technology-enabled primary care intervention with cardiovascular disease risk management in rural Indonesia. JAMA Cardiol. 2019;4(10):97886. https://doi.org/10.1001/jamacardio.2019.2974 PMid:31461123 